\title{
$O$ efeito Salieri: 0 sindicalismo perante as desigualdades entre mulheres e homens no emprego
}

The Salieri Effect: Trade Unionism vis-à-vis the Inequalities between Women and Men in Employment

L'effet Salieri : Le syndicalisme devant les inégalités entre femmes et hommes dans le travail

\section{Virgínia Ferreira}

\section{OpenEdition}

\section{Journals}

Edição electrónica

URL: http://journals.openedition.org/rccs/1328

DOI: $10.4000 /$ rccs. 1328

ISSN: $2182-7435$

\section{Editora}

Centro de Estudos Sociais da Universidade de Coimbra

Edição impressa

Data de publição: 1 Junho 2002

Paginação: 121-148

ISSN: 0254-1106

Refêrencia eletrónica

Virgínia Ferreira, « $\mathrm{O}$ efeito Salieri: O sindicalismo perante as desigualdades entre mulheres e homens no emprego », Revista Crítica de Ciências Sociais [Online], 62 | 2002, colocado online no dia 01 outubro 2012, criado a 30 abril 2019. URL : http://journals.openedition.org/rccs/1328 ; DOI : 10.4000/ rccs. 1328 


\section{VIRGÍNIA FERREIRA}

Faculdade de Economia da Universidade de Coimbra e Centro de Estudos Sociais

\section{O efeito Salieri: $O$ sindicalismo perante as desigualdades entre mulheres e homens no emprego}

Os actuais padrões de segregação sexual do mercado de trabalho são ainda, em parte, a expressão viva de práticas excludentes e segregadoras dos sindicatos desde o começo da revolução industrial. Estes padrões começaram a desenhar-se a partir da aceitação do pagamento de menores salários às mulheres. Só num segundo momento os sindicatos passaram a reivindicar a igualdade salarial entre mulheres e homens como forma de defesa do emprego masculino. Numa primeira parte do texto, dá-se conta de algumas destas práticas de fechamento dos sindicatos em Portugal. Numa segunda parte, referem-se as principais linhas de mudança das orientações do movimento sindical perante as desigualdades entre os sexos no mercado de trabalho e apontam-se algumas iniciativas no âmbito da promoção da igualdade entre mulheres e homens.

\section{Introdução}

Desde há especialmente três décadas que o sindicalismo tem vindo a ser fustigado um pouco por toda a parte com severas críticas por, através da sua acção, não só ter sido cúmplice como também activo promotor das desigualdades entre os sexos no mundo do trabalho e do emprego. Seguindo o padrão de relações sociais de sexo que subordinam e dominam as mulheres, os sindicatos de tudo fizeram no passado para que estas não beneficiassem de igualdade de oportunidades com os homens, tendo, inclusivamente, promovido algumas lutas contra a presença destas nos locais de trabalho.

Em Portugal, os primeiros sinais de inquietação relativamente a estas práticas sindicais tornaram-se visíveis a partir de meados da década de 1980, depois da nossa integração na Comunidade Europeia, devido a uma conjugação de novos fenómenos, provavelmente com algum nexo causal entre si. Em primeiro lugar, refira-se a profunda crise que afecta o sindicalismo em todas as frentes e que se traduz fundamentalmente na perda de associados e de influência e, consequentemente, no enfraquecimento da capacidade 
de mobilização. ${ }^{1}$ Essa crise tem na sua origem, entre outros factores, o desemprego e a flexibilização das situações laborais, resultantes do forte impacte das mudanças tecnológicas e organizacionais, que produzem fenómenos de crescente exclusão social e fragmentação do colectivo operário (Gorz, 1999). Fenómenos estes que culminam num crescente individualismo, fruto da desagregação de interesses, segundo a tese muito difundida e criticada de Richard Hyman (1994). ${ }^{2}$ Em segundo lugar, há que assinalar o impacte das políticas de igualdade de oportunidades entre mulheres e homens da Comunidade Económica Europeia, que criou uma nova conjuntura e estimulou uma inflexão nas práticas sindicais para com as mulheres trabalhadoras.

Por último, é forçoso assinalar aquele que é talvez o principal factor da mudança observada. Durante as décadas de 1980 e 1990, as taxas de participação na actividade económica formal das mulheres não pararam de aumentar em Portugal, como na maioria dos países, de tal forma que hoje em dia as mulheres representam praticamente metade da força de trabalho. Foi, portanto, naturalmente que esta categoria da força de trabalho se impôs como reserva estratégica para a sobrevivência do movimento sindical (DateBah, 1997: 210).

Os obstáculos ao surgimento de novas fontes de recrutamento decorrem, contudo, do facto de os novos empregos se inserirem sobretudo no sector dos serviços e/ou de vínculo laboral precário, caracteristicamente de mais difícil mobilização sindical. Aí estão para o mostrar os resultados de um inquérito recente, conduzido por uma parceria constituída pela Organização Internacional do Trabalho (no âmbito do seu Programa Internacional sobre More and Better Jobs for Women - WOMEMP) e a Comissão de Mulheres da Confederação Internacional dos Sindicatos Livres (CISL) (ILO, 1999). Das 217 respostas recebidas em Março de 1999, a maior parte dos sindicatos dá conta de uma continuada diminuição de filiados/as. Naque-

\footnotetext{
${ }^{1}$ Sobre os problemas que afectam o mundo sindical existe uma vasta bibliografia da qual não cabe aqui dar conta. Encontramos em Ferreira e Costa (1998/99) referência a um largo conjunto de obras que abordam a questão tanto em termos gerais como no plano nacional. Dentre os trabalhos específicos sobre Portugal, merece destaque o trabalho de Maria Teresa Serôdio Rosa (1998).

2 Esta tese tem sido criticada, nomeadamente porque, na perspectiva das mulheres trabalhadoras, ela contém implícita a referência a uma idade de ouro que no passado se teria caracterizado pela homogeneidade do movimento sindical, deixando na obscuridade a fragmentação existente anteriormente e a hostilização e exclusão a que as mulheres foram expostas. $\mathrm{Na}$ minha apreciação, porém, tanto a tese de Hyman como a sua crítica devem ter em conta dois aspectos interligados. Um será sem dúvida as mudanças ao nível da composição sexual da força de trabalho (muito presente na leitura de Hyman e negligenciada na crítica que lhe é feita). O outro é a transformação ideológico-política, nomeadamente a crescente influência da dissidência feminista (muito enfatizada na crítica de Hyman e ignorada por este).
} 
les que registam aumentos, porém, os ganhos são conseguidos à custa da adesão das mulheres (ILO, 1999: quadro 2). Cerca de 33\% dos sindicatos apresenta uma taxa de feminização inferior a $30 \%$ e em $60 \%$ deles as mulheres não ultrapassam os $50 \%$, mesmo nos sectores de emprego mais feminizados. Um outro estudo, realizado em dois momentos - 1993 e 1998 - pela Confederação Europeia de Sindicatos, através também de inquérito dirigido às organizações sindicais suas filiadas em 28 países e ao qual responderam 42 confederações a nível europeu, confirmou tendências similares (CES, 1999). A taxa média de feminização nos países europeus anda à volta de $40 \%$, mas as diferenças são muito díspares: desde os $10 \%$ na Turquia até aos $70 \%$ na Islândia. O que estes inquéritos vieram confirmar é que as mulheres continuam a sindicalizar-se menos do que os homens, muito embora nada justifique que se perpetue a imagem do seu alheamento da actividade sindical. ${ }^{3}$

Neste texto procurarei trazer à tona de água algumas dessas práticas sindicais que no passado conduziram à presente situação. Não constituindo esta démarche uma revelação propriamente dita porque aquelas práticas são já bem conhecidas, o meu propósito é antes começar por mostrar os seus efeitos nos padrões de segregação do emprego e nas desigualdades no acesso ao emprego, a qualificações e remunerações compatíveis. ${ }^{4}$ Numa segunda parte do artigo, serão explorados alguns dos mais recentes discursos e práticas do movimento sindical, especialmente em Portugal, sobre a igualdade entre mulheres e homens no trabalho e no emprego. Apesar do estudo restringir o seu âmbito à realidade nacional, serão feitas referências

\footnotetext{
3 Apesar de algumas organizações registarem uma redução dos seus efectivos, como as Comisiones Obreras (CCOO) em Espanha e a Confederação Sindical Alemã (DGB) na Alemanha, a maior parte dá conta de um pequeno aumento de cerca de 2\%, entre 1993 e 1998 (CES, 1999: 12). Relativamente às duas centrais sindicais nacionais, não é possível saber qual foi a evolução. A CGTP-IN, a maior delas, não informa qual é a percentagem de mulheres entre os seus filiados em nenhum dos dois anos e a UGT informou que esta percentagem era de $41 \%$ em 1993, mas em 1998 já não fornece esta informação... No Congresso da UGT em 2000, foi anunciado que, nos 16 sindicatos que haviam respondido a um questionário lançado, e que representam cerca de $30 \%$ das organizações sindicais filiadas na central, as mulheres representavam em média 39,3\%.

Sinais positivos são avançados por Graciete Cruz, que coordena a Comissão Nacional das Mulheres da CGTP-IN, em entrevista concedida à equipa responsável pelo projecto "Género e Estruturas de Decisão nos Sindicatos” do Centro de Estudos de Género da Universidade Lusófona e da Direcção Geral das Condições de Trabalho, que é coordenada por Vera Santana e Maria João Janeiro. Segundo as declarações dessa dirigente sindical, durante o ano de 2000, esta central registou a entrada de 56443 novas sindicalizações, das quais 48,5\% eram de mulheres. Também a eleição de delegados sindicais no mesmo ano trouxe $42,4 \%$ de mulheres para este cargo, o que mostra que ao nível dos locais de trabalho as mulheres tendem a participar mais (agradeço a Vera Santana o acesso a esta entrevista).

${ }^{4}$ Para a definição das modalidades de segregação horizontal, vertical e transversal do mercado de trabalho em função do sexo, veja-se Ferreira (1993).
} 
às tendências observadas nas principais confederações sindicais a nível europeu, incontornáveis fontes normativas de orientações das duas centrais sindicais portuguesas.

\section{As estratégias de fechamento dos sindicatos}

As estratégias de fechamento dos sindicatos são essencialmente de dois tipos: o da exclusão pura e simples do direito de filiação sindical e de acesso ao emprego e o da segregação das mulheres em sectores específicos de emprego com baixos estatuto e remuneração. A segunda estratégia foi gradualmente substituindo a primeira, a partir de meados do século Xx, à medida que as mulheres forçavam a sua entrada no mercado de trabalho e adquiriam mais direitos civis e políticos, entre os quais é justo sublinhar o direito ao voto.

O estudo das práticas sindicais de discriminação da mão-de-obra feminina iniciou-se durante a década de setenta, de forma sistemática, em especial nos EUA, e a bibliografia que dele dá conta é muito vasta. ${ }^{5}$ Para Portugal, apenas encontrei dois pequenos textos de análise sobre as mulheres e o sindicalismo, reportando-se ambos a situações dos finais da década de 1980: um é de Maria Teresa Serôdio Rosa (1991) e incide sobre as representações e as práticas sindicais de um grupo de mulheres operárias, mostrando como a predominância do controlo coercivo nas empresas em que a mão-de-obra feminina é maioritária obstaculiza o surgimento do sindicalismo contestatário; o outro é um pequeno texto de Isabel Margarida André (1995), no qual são respigadas algumas das conclusões a que uma análise promovida pela CGTP-IN a 69 convenções colectivas de trabalho tinha chegado. De resto, encontramos na obra de Fátima Patriarca, notável enquanto análise das práticas corporativistas, em especial durante as décadas de 30 e 40, muitas informações sobre práticas sindicais, patronais e estatais que nos permitem ir construindo uma imagem, ainda que não sistemática, das respectivas estratégias de exclusão e segregação do emprego e de discriminação salarial das mulheres (Patriarca, 1990, 1994). Também na obra de Irene Pimentel sobre as organizações femininas no Estado Novo, são referenciadas algumas destas práticas (2000: 41-47).

O primeiro erro do movimento sindical terá consistido em concordar com o pagamento de salários inferiores às mulheres pela realização de tarefas similares às dos homens. Depois, face ao espectro da generalização da contratação de mulheres, lutou por impor barreiras à sua contratação, em

\footnotetext{
${ }^{5}$ Veja-se, meramente a título ilustrativo, para os EUA, Hartmann (1976) e Epstein (1988); para a França, Zylberberg-Hocquard (1978); e, para a Inglaterra, Murgatroyd et al. (1984), Walby (1990) e Scott (1998).
} 
vez de reivindicar salários iguais para todos. Só mais tarde se impôs o entendimento de que era no interesse da defesa do próprio emprego masculino que se deveria lutar pelo princípio da igualdade de salários para mulheres e homens. Mas vejamos alguns exemplos dessas estratégias e os respectivos efeitos.

Uma das estratégias usadas pelos sindicatos para restringir o acesso das mulheres ao emprego passou pela negação do direito de filiação das mulheres nos sindicatos. Tratou-se de uma prática corrente que, como é do conhecimento geral, vigorou sobretudo durante a regência do closed shop. ${ }^{6} \mathrm{Em}$ Portugal, as práticas do closed shop, ilegalizadas por despacho de 1943, nunca chegaram a ter a importância que tiveram na Grã-Bretanha ou que vieram a ter mais tarde nos Estados Unidos da América, até porque o patronato não cumpria os acordos (Patriarca, 1990:361). Mesmo assim, os sindicatos tendiam "a restringir o acesso das mulheres, impedindo-as de exercer a profissão ou arredando-as de certos trabalhos e funções”, como escreve Fátima Patriarca (1990: 607). Ao contrário num país como a Inglaterra, em que houve um movimento sufragista forte, que conseguiu mobilizar as mulheres trabalhadoras, esta interdição de afiliação levou à criação de sindicatos só de mulheres, de que a Federação Nacional de Mulheres Trabalhadoras (National Federation of Women Workers), a Liga dos Sindicatos de Mulheres (Women's Trade Union League) (Walby, 1990: 189) e a Liga das Cooperativas de Mulheres (Women's Co-operative Guild) (Scott, 1998) são exemplos paradigmáticos.

Outras estratégias passaram pela proibição da contratação de mulheres ou apenas de mulheres casadas, para certos postos de trabalho e até mesmo pela imposição de esquemas complexos de contagem de tempo de serviço que impedissem que as mulheres se sobrepusessem em antiguidade aos homens. O Estado, como é sabido era o primeiro a impor e a promover estas práticas, pois também enquanto empregador impôs múltiplas interdições à contratação de mulheres. Entre nós, as mulheres estiveram legalmente impedidas de ingressar em algumas profissões até depois do 25 de Abril de 1974, enquanto noutras profissões a interdição aplicava-se apenas às mulheres casadas. ${ }^{7} \mathrm{Um}$ despacho relativo ao sector da chapelaria, pouco

\footnotetext{
${ }^{6}$ A prática do closed shop resulta de acordos entre sindicatos e patronato para que a mão-de-obra empregue seja necessariamente filiada nesses sindicatos. Como é evidente, os sindicatos vetavam a filiação a "colegas indesejados" (Watson, 1987: 283).

7 A proibição do emprego de mulheres englobou a carreira diplomática, a magistratura judicial, a chefia da administração local e os postos de trabalho no Ministério das Obras Públicas e Comunicações. Estas disposições estavam incluídas no Código Administrativo de 1936 e só viriam a ser revogadas depois do 25 de Abril de 1974: o Decreto-Lei n. ${ }^{\circ}$ 251/74, de 12 de Junho, abriu a
} 
antes de 1935, proibiu a presença de mulheres em todos os trabalhos que não fossem de costura desde que houvesse desempregados masculinos adultos maiores de 21 anos, inscritos nos sindicatos nacionais (Pimentel, 2000: 44). ${ }^{8}$ Estas mesmas restrições verificaram-se também na têxtil de algodão, na de seda natural e artificial e na tipografia (onde era vedado o acesso de mulheres aos serviços de composição e impressão). Nos Corticeiros de Aveiro (1938) e nas Salinas de Lisboa, Setúbal e Algarve (1939) também se restringiu o acesso de mulheres e de menores (Patriarca, 1994: 815). Irene Pimentel também dá conta de várias proibições em sectores da indústria: nos sectores que lidavam com substâncias tóxicas e perigosas e nos postos de trabalho que lidavam com máquinas na indústria das conservas, na panificação industrial e na carga e descarga no Rio Douro (Pimentel, 2000: 44).

Outra limitação imposta quer por legislação quer por acordos colectivos sectoriais diz respeito à proporção de mulheres empregadas que as entidades patronais estavam obrigadas a não ultrapassar "em nome da defesa da maternidade e do interesse da nação": na indústria da cerâmica, um despacho do INTP de 13 de Setembro de 1939 proibiu a admissão de pessoal feminino numa percentagem que excedesse $15 \%$ de todo o pessoal e, em 1942, os trabalhos que, "pela sua natureza, pertençam aos homens" foram vedados às mulheres; na indústria de malhas e passamanarias, um despacho impôs em 1936 a substituição de mulheres por homens nas máquinas manuais; na indústria conserveira, os contratos colectivos da Indústria de Conservas do Barlavento e Sotavento Algarvio (16/1/1938), de Setúbal $(17 / 2 / 1938)$ e de Leiria (27/9/1938) regulamentavam a passagem a efectivo

carreira na administração local às mulheres; o Decreto-Lei n. ${ }^{\circ}$ 308/47, de 6 de Julho, revogou a proibição da admissão das mulheres ao serviço diplomático; e, por fim, o Decreto-Lei n. ${ }^{\circ}$ 492/74, de 27 de Setembro, possibilitou às mulheres o exercício de cargos judiciários do Ministério Público (juiz de direito, delegados procuradores da República). A interdição de acesso aos postos de trabalho no Ministério das Obras Públicas e Comunicações foi levantada em 1962, por ter sido considerada inconstitucional.

Quanto à barreira matrimonial ela foi imposta em várias profissões. A proibição do casamento das empregadas do Ministério dos Negócios Estrangeiros foi regulada pelo Decreto-Lei n 29970 de 13 de Outubro de 1939. No começo desse mesmo ano, a companhia dos telefones tinha imposto essa proibição às suas telefonistas. Em 1942, tinha sido instituída a proibição matrimonial às enfermeiras dos hospitais civis, pelo Decreto-Lei n. ${ }^{\circ}$ 31913, de 12 de Março. Quanto às hospedeiras de ar, o casamento foi regulado por uma ordem de serviço da TAP de 1955 (ordem de serviço n. ${ }^{\circ} 18$ ). A primeira revogação desta proibição ocorreu muito pouco tempo depois, em 1940, e abrangeu as telefonistas. As restantes só ocorreram mais de vinte anos depois, com o novo Código Civil de 1967 (informações colhidas em Pimentel, 2000: 39 ss).

${ }^{8}$ Perante a reacção das operárias e dos industriais de São João da Madeira, a 14 de Agosto de 1935, são concedidas licenças de trabalho à mão-de-obra feminina em fábricas que, à data de 20 de Julho do mesmo ano, já empregassem mulheres, ainda que apenas em certas condições e em número limitado, na afinação, coja mecânica e arcagem de lã (Patriarca, 1994: 815). 
dos operários maiores de 18 anos e estipulavam que, uma vez fixado "o número de operárias, nenhuma fábrica poderá ter ao serviço pessoal feminino em número superior a $1 / 5$ e $1 / 6$ do pessoal feminino do quadro efectivo" (Pimentel, 2000: 48).

Gostaria de abrir aqui um parênteses, para sublinhar que não podemos, em meu entender, argumentar que estas práticas eram o resultado ou da imposição do Estado ou da natureza corporativa dos sindicatos que fazia com que estes não fossem nem livres nem independentes. Em primeiro lugar, há que constatar a unanimidade de opinião que existia entre as várias correntes sindicais quanto a estas matérias. Com efeito, tanto a tendência anarquista como a comunista responsabilizavam a inserção das mulheres no emprego pelos elevados níveis de desemprego e pelos baixos salários praticados. A central sindical comunista era formalmente contra esta tese, mas entre as bases ela era muito perfilhada. Em 1931, Bento Gonçalves viu-se obrigado a intervir para impedir a expulsão das mulheres pretendida pela direcção do Sindicato dos Manipuladores de Pão do Porto (Patriarca, 1990: 121). ${ }^{9}$ Em segundo lugar, os testemunhos e as análises que nos chegam de outros países confirmam a ampla difusão que estas práticas sindicais de fechamento e de exclusão tiveram, mesmo nas sociedades que permitiam um sindicalismo livre (vejam-se os exemplos dos Estados Unidos da América, da Inglaterra ou da França, já mencionados).

Apesar de, desde 1979, estar em vigor entre nós a lei que instituiu o direito à igualdade das mulheres no trabalho e no emprego (Decreto-Lei n. ${ }^{\circ} 392 / 79$, de 20 de Setembro), ${ }^{10}$ a qual criou mesmo uma Comissão para a Igualdade no Trabalho e no Emprego (CITE) estruturada com o concurso do governo e dos parceiros sociais, em meados da década de 1990, de acordo com o estudo de 75 instrumentos de regulamentação colectiva, realizado pela CGTP-IN, algumas convenções colectivas de trabalho ainda consagravam no nosso país a exclusão das mulheres de certos postos de trabalho. ${ }^{11}$ Para além do caso do trabalho no fundo das

\footnotetext{
9 Diga-se de passagem que esta ideia está ainda hoje presente em muitos modelos analíticos do desemprego. Marinús Pires de Lima aponta como causas do desemprego durante a segunda metade da década de setenta a diminuição da emigração, o retorno das ex-colónias, a feminização do mercado de trabalho e os despedimentos (Lima, 1991: 912). Ora, só por se ter um modelo masculino do desemprego é que se pode afirmar que uma das causas deste é a feminização do emprego. ${ }^{10}$ Esta lei tem vindo a ser revista mais ou menos de $9 \mathrm{em} 9$ anos. Foi revista em 1988 pelo Decreto-Lei n. ${ }^{\circ}$ 426/88, de 18 de Novembro, que redefiniu em especial as atribuições da CITE, e em 1997 pela Lei n. ${ }^{\circ}$ 105/97 de 13 de Setembro, que veio finalmente fornecer os meios que garantem o exercício efectivo do direito à igualdade no trabalho e no emprego.

${ }^{11}$ Estudo interno da CGTP não publicado, cujo acesso aqui agradeço. Este estudo veio mostrar que a situação pouco havia mudado desde uma primeira análise, realizada em 1988 a 69 convenções colectivas de trabalho (referido em André, 1995).
} 
minas (a que apenas as mulheres com funções técnicas podiam ir), que é mais conhecido, existiam ainda situações de exclusão de 14 categorias profissionais na indústria têxtil algodoeira, malhas e tapeçarias, na de oleiro sanitário na indústria de cerâmica (barro branco) e em algumas outras categorias da indústria corticeira (CGTP-IN, 1999). ${ }^{12}$ A Comissão para a Igualdade no Trabalho e no Emprego, por seu turno, fez divulgar num folheto os Instrumentos de Regulação Colectiva do Trabalho que, em 1992, ainda continham designações de profissões apenas no feminino, apesar de tal prática ser expressamente proibida pelo art. 9. ${ }^{\circ}$ do Decreto-Lei n. ${ }^{\circ} 392 / 79$, de 20 de Setembro, que estipula mesmo o efeito nulo das disposições que violem o princípio da igualdade. Os exemplos percorrem os mais diversos sectores de actividade económica. Desde a Agricultura à Indústria Alimentar, Têxtil, de Papel e Artes Gráficas, Metalúrgica, Química, Madeira e Cortiças, e Outras Indústrias Transformadoras, à Indústria Hoteleira, ao Comércio, Transportes, Comunicações, Serviços Prestados à Colectividade e Serviços Recreativos e Culturais. As designações mais recorrentes são a de Empacotadeira, Secretária de Direcção, Costureira, Lavadeira, Educadora de Infância, Preparadora e Manicura.

O caso do calçado é conhecido e ilustra bem quer o fenómeno da segregação quer o das desigualdades salariais. Neste sector são estabelecidos duas fileiras profissionais, de acordo com o contrato colectivo de trabalho, negociado por equipas que até há pouco tempo não integravam mulheres, apesar de o sector do calçado registar uma taxa de sindicalização feminina de $40 \%$, uma das mais elevadas a nível nacional. Assim, é no grupo B, com menores salários, que se agregam as categorias profissionais "femininas", muito embora todas as designações sejam feitas no masculino, e se concentravam, em 1994, 88\% das trabalhadoras do sector. Apesar de os sindi-

\footnotetext{
${ }_{12}$ Este é um estudo que mereceria uma outra atenção por parte da sociologia do trabalho em Portugal. Esta iniciativa da CGTP-IN que, como veremos adiante, foi prosseguida posteriormente, indicia interesse por este aspecto da prática sindical e o seu aprofundamento seria extremamente importante para o nosso conhecimento da história do trabalho das mulheres portuguesas. Até porque estes estudos só podem ser tomados como uma aproximação exploratória da questão, uma vez que o procedimento de recolha de informação adoptado foi um questionário dirigido às direcções sindicais que, como é referido no relatório do primeiro levantamento, não puderam ou não quiseram responder com rigor e exaustividade. Por outro lado, é extremamente difícil a alguém que não conheça a fundo o processo de trabalho descobrir as fontes de discriminação, que estão muitas vezes veladas por formulações ou cláusulas da contratação colectiva aparentemente inócuas, pelo que o concurso de pessoas bem conhecedoras dos processos produtivos é indispensável. O ideal seria, quer-nos parecer, aliar a análise jurídica e sociológica dos instrumentos de regulação colectiva do trabalho com entrevistas com pessoas experientes em cada ramo de actividade.
} 
catos terem começado a tentar combater esta discriminação, a situação mantém-se. ${ }^{13}$

Em estudo posterior, do qual voltarei a falar mais adiante - o Projecto NOW-LUNA (1996-2000), cuja entidade promotora foi a Comissão Nacional de Mulheres da CGTP-IN - a análise de 16 instrumentos de regulação colectiva de trabalho (IRCT) concluiu que

Existe ainda um grupo de IRCT's, que, por violarem já normas imperativas, no tocante à organização do trabalho, contêm normas discriminatórias relativamente às mulheres porque as excluem expressamente, nomeadamente os IRCT's do Comércio Retalhista e Grossista de Lisboa, Vestuário e Confecções, Cantinas e Refeitórios e Fábricas de Refeições e Hotelaria e Restauração do Norte de Portugal e Indústria e Comércio Farmacêutico. (http://www.cgtp.pt/index2.htm) ${ }^{14}$

Estes procedimentos expressam uma prática de fechamento social da mesma natureza das descritas por Frank Parkin (1974) como processos através dos quais as colectividades procuram maximizar os seus privilégios, restringindo o acesso e as oportunidades a um apertado círculo de elegíveis. Hoje em dia, estas situações continuam a merecer uma atitude mais ou menos passiva por parte dos sindicatos. Cristalizações de práticas do passado, não concitaram ainda uma mobilização sindical efectiva e estratégica

${ }_{13} \mathrm{O}$ sector do calçado é dos sectores em que se verifica maior discriminação. Elísio Estanque concluiu que na região de S. João da Madeira, dominada pela indústria do calçado, as mulheres estão mais afastadas das posições de poder (gestores e supervisores), do que na sociedade em geral (2000: 215). Os sindicatos introduziram a reivindicação da eliminação da discriminação sexual nas classificações profissionais e nas remunerações de forma mais decidida na negociação colectiva durante o processo negocial que decorreu em Janeiro de 1998 entre o Sindicato dos Operários da Indústria do Calçado, Malas e Afins dos Distritos de Aveiro e Coimbra, reunidos na FESETE (Federação dos Sindicatos das Indústrias Têxteis, Vestuário e Calçado), uma federação filiada na CGTP-IN, e a APICCAPS (Associação Portuguesa dos Industriais de Calçado, Componentes e Artigos de Pele e seus Sucedâneos) (conforme dados referidos em Cristovam, 1998). Em Janeiro de 2002, no próprio dia em que estou a terminar este texto, é noticiada uma manifestação promovida pelo sindicato acima referido, exigindo igualdade de remuneração para mulheres e homens junto de uma das maiores empresas do sector. A manifestação é anunciada pelo jornalista da RTP1 como "uma manifestação com uma reivindicação muito pouco comum" e na reportagem era entrevistado o director de recursos humanos da empresa que afirmava que "a empresa se limitava a cumprir a lei ...", isto é, o acordo colectivo para o sector. O facto de a actual direcção do sindicato apresentar uma composição paritária, quatro mulheres e quatro homens, pesa certamente sobre a iniciativa de introduzir esta reivindicação.

${ }_{14}$ Para vermos a atitude cautelosa com que os meios sindicais ainda tratam estas questões, não deixa de ser interessante notarmos que este parágrafo, retirado da internet em Janeiro de 2002, tenha sido excluído da publicação que apresentava o relatório final do projecto (CGTP-IN, 2000). 
para a sua erradicação. Alguns sinais de mudança se perscrutam, contudo, no horizonte (veja-se o que foi referido a propósito da actuação sindical no sector do calçado). Abordá-los-emos no final deste texto.

\section{Os efeitos segregadores das práticas sindicais}

Os padrões de segregação observados em cada grupo de profissões ou em cada sector de actividade são, como não podia deixar de ser, o resultado das práticas de recrutamento e de estruturação das carreiras exercidas no passado, bem assim como da trajectória e evolução das profissões, e é possível neles detectar o rasto das referidas práticas sindicais de exclusão e de segregação sexual.

Em linhas muito gerais e grosseiras, pode afirmar-se que algumas das profissões mais segregadas, como é o caso das manuais indiferenciadas, são precisamente aquelas em que as qualificações exigidas são muito semelhantes para ambos os sexos, mas que têm conteúdos funcionais muito rígidos, basicamente compostos por rotinas pouco ou nada diversificadas (de que são bons exemplos muitas classificações profissionais de 'operadores' incluídas no grupo 8 da CNP de 1994 - Classificação Nacional de Profissões designado Operadores de Instalações Industriais e Máquinas Fixas, Condutores e Montadores).

Outro dos grupos mais segregados é o dos ofícios manuais qualificados, cujos sindicatos optaram claramente por uma estratégia de exclusão das mulheres, da qual terá resultado o baixo grau de feminização que estas profissões continuam a ter. Incluídas neste grupo encontram-se muitas profissões do grupo $7 \mathrm{da}$ CNP, designado Trabalhadores da Produção Industrial e Artesãos, mas também dos grupos 3 e 4 (electricista de rede, carpinteiro naval, desenhador, modelador, etc.). ${ }^{15}$ Ao contrário, as de conteúdo mais indefinido, abrangente e diversificado e de fronteiras mais fluidas tendem a ter um estatuto mais plural. Os sindicatos mais "generalistas", que agrupam trabalhadores semi-qualificados ou indiferenciados e que foram criados num período mais recente, optam mais frequentemente por estratégias de segregação das mulheres em determinados postos. Verifica-se, com efeito que, em termos temporais, o recurso à prática da segregação, em vez da exclusão, foi mais frequente num segundo momento, quando as mulheres já podiam lutar pela defesa do seu emprego nos locais de trabalho (Walby, 1990: 54-55).

\footnotetext{
${ }^{15}$ Conforme dados disponíveis, mas não publicados dos Quadros de Pessoal (Departamento de Estatística do Trabalho, Emprego e Formação Profissional do Ministério do Trabalho e da Solidariedade), do ano de 1998.
} 
Estas tendências são consensualmente apontadas pela generalidade de analistas que se tem debruçado sobre esta questão (por exemplo, Crompton e Sanderson, 1990: 42; Walby, 1990: 54). Registam-se, contudo, algumas nuances. Por exemplo, a argumentação de Tony Watson (1987: 125) é convergente com a de Walby, mas enfatiza um outro aspecto. Segundo o autor, os sindicatos dos ofícios tradicionais e as organizações das profissões liberais, enquanto herdeiros mais directos das antigas formas de organização profissional, que eram estruturadas segundo o princípio ocupacional, prosseguem estratégias mais exclusivistas, em nome do "bom nome da profissão". Sendo os outros sindicatos organizados em torno do princípio administrativo, por exemplo, o sector de actividade ou da região, as suas estratégias tendem a ser menos segregativas porque o seu objectivo é a defesa dos interesses dos empregados e não dos profissionais. É por isso que a organização vertical, de base sectorial ou regional, está associada a menores índices de segregação.

Mas, evidentemente, será muito temerário estabelecer regras gerais quanto a estas tendências. Só a análise de cada situação concreta pode revelar os processos de segregação e discriminação salarial e os seus respectivos efeitos, detectáveis nas estruturas do emprego. Já tive oportunidade de defender que uma das razões pelas quais existe uma menor segregação sexual do mercado de trabalho em Portugal passa precisamente pelo défice sindical que marca a sociedade portuguesa e pela predominância da estruturação vertical em função dos sectores de emprego da maior parte dos sindicatos no nosso país (Ferreira, 1993: 252). Mais forte fosse o movimento sindical e mais organizado no princípio profissional, mais segregado seria o nosso mercado de trabalho, conclusão sugerida, por exemplo, pela comparação com o que se passa noutros mercados de trabalho, em especial os dos países nórdicos. ${ }^{16}$

Entre analistas, corre um consenso em torno da tese de que quanto mais forte for o movimento sindical mais capaz é de impor as suas lógicas de exclusão e segregação. Em Portugal, os casos dos sindicatos dos bancários e dos agentes de seguros ilustram bem esta tese. A acção dos sindicatos bancários na fase de implantação do sector em Portugal, que surgiu como exemplo modelar e pioneiro do sindicalismo organizado segundo o princípio profissional, foi extremamente importante para estruturar as bases de um estatuto social e de remuneração elevados que parecem estar hoje a ser novamente reforçados. Por outro lado, a prática de controlo de acesso à

\footnotetext{
${ }^{16} \mathrm{Na}$ verdade, os países nórdicos têm em geral elevadas taxas de sindicalização, conforme estudo citado da Organização Internacional de Trabalho (ILO, 1999) e, ao mesmo tempo, registam uma forte segregação sexual nas estruturas de emprego (Ferreira, 1993).
} 
profissão exercida a partir dos anos 30 criou uma tradição de recrutamento de mão-de-obra masculina que produz até hoje os seus efeitos. A história sindical mostra efectivamente que este sector foi um dos poucos que, na fase de implantação do sindicalismo corporativo em Portugal, a partir os anos 30, aderiram ao sistema dos contratos de closed shop (Patriarca, 1990: 346 ss). A justificação dada para estes contratos era a luta contra o desemprego dos anos 30 e a deserção sindical, em consequência da repressão do Estado Novo. Como afirma Fátima Patriarca

em quase todos os contratos - até mesmo nos das classes médias assalariadas, ao contrário do que se poderia imaginar - deparamos com cláusulas que dão preferência ou mesmo restringem a admissão de aprendizes ou de trabalhadores adultos aos familiares dos profissionais que já se encontram ao serviço. Instala-se uma espécie de princípio hereditário ao nível profissional, mas também o fecho da profissão a uma excessiva concorrência, o qual redunda, por sua vez, no reforço dos mecanismos de controlo do mercado de trabalho através dos próprios laços familiares. (1990: 607)

A autora enumera em nota de pé-de-página os contratos dos sindicatos das "classes médias assalariadas" que se inspiram neste sistema. Tratava-se do Sindicato dos Trabalhadores dos Seguros de Lisboa e Porto, da Secção de Seguros do Sindicato Nacional dos Trabalhadores do Comércio do Distrito de Évora, dos Sindicatos dos Bancários e de pequenos segmentos dos Empregados de Escritório, nomeadamente, dos Empregados dos Escritórios dos Importadores de Arroz e Bacalhau de Lisboa e do Porto e o Sindicato dos Guarda-Livros e Contabilistas do mesmo ramo de actividade. A prática descrita de controlo de acesso à profissão constitui, sem dúvida, uma das principais razões por que os bancos e os seguros são ainda dos sectores mais masculinizados dos empregos de escritório no nosso país, especialmente quando comparados com o que se passa em outros países europeus (Larangeira e Ferreira, 2000).

Deve apontar-se, no entanto, que a importância da acção sindical na segregação vertical da divisão sexual de trabalho não é reconhecida por muitos autores, que contestam a força dos sindicatos para fazerem esse tipo de imposição às políticas patronais de recrutamento e de promoção da mão-de-obra. Esta argumentação reforça-se na constatação da persistência da segregação vertical mesmo naqueles sectores de emprego em que os sindicatos são manifestamente pouco poderosos, como é o caso do sector dos escritórios em geral (Cohn, 1985; Walby, 1990). De qualquer modo, não será de rejeitar, per se, a força do efeito de demonstração de articulados 
legais ou de acordos sectoriais segregativos, de que é exemplo maior a proibição do emprego de mulheres casadas como enfermeiras hospitalares e operadoras de telefone, e a sua contaminação para os restantes sectores de emprego. Por fim, é preciso ter em conta que, subjacente a esta questão da integração ou não das mulheres em qualquer posto de trabalho, está a preocupação com o impacte no emprego masculino dessa integração, como é inevitável, mas também nos salários dos trabalhadores do sector. Vejamos, então, como é que as tomadas de posição sindicais face ao emprego e à remuneração das mulheres se articularam no passado.

\section{Os sindicatos e a luta pelo salário igual a trabalho de valor equivalente}

Em Portugal, os governos impuseram e foram, e continuam a ser, coniventes com acordos colectivos de trabalho que consagram o princípio da desigualdade salarial entre mulheres e homens. Vejamos alguns exemplos.

A regulamentação do trabalho feita pelo regime corporativo abrangia as diferenças salariais entre mulheres e homens. Por exemplo, um despacho governamental de 1935, para o sector da chapelaria, fixava salários mínimos diários para várias categorias do pessoal masculino, bem como o preço do trabalho à peça por tipo de trabalho e de chapéu; em contrapartida fixava um salário único, diário e inferior para as mulheres (Patriarca, 1994: 815). Por seu turno, os sindicatos, muito embora formalmente já defendessem o princípio de "a trabalho igual, salário igual" desde 1931, acabavam por negociar acordos colectivos que consagravam diferenciais salariais em desfavor das mulheres, por vezes até tentando impor tectos mínimos para esse diferencial.

Mais uma vez encontramos nas obras de Fátima Patriarca e de Irene Pimentel exemplos de sobra que ilustram estas práticas. O contrato colectivo de trabalho de 1943 impunha na indústria de bordados da Madeira, na qual a mão-de-obra feminina era largamente maioritária, um salário mínimo inferior em $42 \%$ ao dos "serventes". Na indústria dos lanifícios, as operárias não especializadas ganhavam menos $40 \%$ do que os homens em 1939, e na categoria de operária especializada de primeira categoria devia auferir, segundo o acordo colectivo de trabalho de 29 de Novembro de 1943, um salário mínimo $53 \%$ inferior ao do operário especializado (Pimentel, 2000: 47).

Fátima Patriarca refere-se por exemplo à

série de acordos do sector corticeiro, celebrados ao longo do ano de 1942, em Almada, Montijo, Sines, Faro, Barreiro e Évora, em que se fixaram os seguintes subsídios provisórios: uns sob a forma de quantitativo fixo (mensal, diário ou horário), corres- 
pondendo os mais elevados a $40 \$ 00$ e $20 \$ 00$ mensais por 26 dias de trabalho, respectivamente para os operários com mais de 21 anos e para as operárias com mais de 18 anos; outros em forma de percentagem sobre os salários e preços de empreitada em vigor em Abril desse ano, situando-se aquela em 10\% para os operários casados e em 5\% para os solteiros e para as mulheres. (Patriarca, 1994: 835)

Como se pode confirmar por esta última disposição, que diferencia entre, por um lado, trabalhadores casados, e, por outro lado, todos e todas os/as restantes - trabalhadores solteiros e trabalhadoras casadas e solteiras - a protecção do papel masculino de provedor da família é a única justificação que encontramos, a par da satisfação das reivindicações dos sindicatos em torno do "salário familiar" que decorria da mesma ideologia discriminatória. O ideal do Estado Novo, que a este não se restringia contudo, passava pelo trabalho das mulheres ao domicílio, já que o precário rendimento das famílias implicava ou "miséria material dos filhos se a mãe não exercesse um trabalho assalariado, ou a miséria moral dos filhos, abandonados pela mãe a trabalhar fora de casa". ${ }^{17}$

Compreende-se, assim, que, apesar de a figura de "chefe de família" já não existir desde 1978 - data de entrada em vigor do novo código civil pós 24 de Abril de 74 - ainda nos finais dos anos 80, em convenções colectivas de trabalho, se fazia referência a essa condição como critério de preferência no recrutamento (André, 1995: 487) e que, apesar de o princípio do salário igual para trabalho igual vigorar desde o fim dos anos sessenta (Decreto-Lei n. ${ }^{\circ} 49408$ de 24/11/69, art. 116, n. ${ }^{\circ}$ 2), o diferencial salarial entre o salário médio masculino e o salário médio feminino ainda hoje se situe apenas um pouco acima dos $75 \%$.

Os exemplos apontados ajudam-nos a compreender por que é que os diferenciais salariais entre homens e mulheres que trabalham na indústria são ainda hoje os mais elevados, por comparação relativamente aos restantes sectores de emprego. A tradição e a organização sindical foi evidentemente muito mais marcante deste sector de emprego, como já vimos atrás.

$\mathrm{Na}$ verdade, instituir a igualdade salarial poderia então ter sido importante para afirmar os princípios liberais da igualdade entre cidadãos, mas a legislação inscrevia-se numa lógica que, por definição, ignorava toda a realidade social, económica e até jurídica produtora das desigualdades entre as mulheres e os homens, na qual o salário é apenas a expressão das desi-

\footnotetext{
17 Segundo intervenções do deputado Almeida Garrett nos anos 50, na Assembleia Nacional, referidas por Pimentel (2000: 47).
} 
gualdades construídas a partir das modalidades de inserção das mulheres no sistema de emprego e no princípio hierárquico entre os sexos inscrito na matriz social, em sentido amplo. ${ }^{18}$

Verdadeiramente inovador é, ou teria potencialidades de o ser, o já referido Decreto-Lei n. ${ }^{\circ}$ 392/79, de 20 de Setembro, que institui expressamente, no seu art. 9. ${ }^{\circ}$ a igualdade de remuneração entre mulheres e homens "por um trabalho igual ou de valor igual" prestado à mesma entidade patronal. Ora, uma das dificuldades está precisamente em que a aplicação da legislação da igualdade salarial é restringida aos casos em que numa mesma entidade patronal são pagos salários diferentes a mulheres e a homens para ocuparem os mesmos postos de trabalho. A possibilidade de diferenciar salários a partir de pequenas diferenças de funções continua, no entanto, a não ser prevenida, como já foi referido a propósito do calçado. Os exemplos noutros sectores poderiam multiplicar-se. ${ }^{19}$ Toda a questão se centra nas concepções adoptadas quer para trabalho igual quer para salário igual. As leis limitam-se frequentemente a estabelecer princípios gerais e abstractos, descurando a regulamentação de situações concretas que ficam depois sujeitas à "livre interpretação" dos agentes sociais (Santos, 1989).

As estratégias sindicais, que aqui constituem o foco da nossa atenção, também são relevantes na definição destas questões. As suas reivindicações têm variado conforme as características da composição sexual do emprego nos vários sectores. Os sindicatos dos sectores de emprego com salários mais altos em que as mulheres são uma minoria acantonada em certas ocupações mais ou menos marginais (como a indústria automóvel) reivindicam em geral "salário igual para trabalho igual". Aqueles em que os salários são baixos e os homens se encontram em minoria nas ocupações mais qualificadas e remuneradas (como a indústria electrónica) optam por exigir "salário igual para trabalho de igual valor" (Milkman, 1987).

A lei portuguesa, como vimos, também se refere a "trabalho igual" ou "trabalho de valor igual”, mas não estabelece, em concreto, nenhum quadro de referência para a sua aplicação. O trabalho igual será aquele que tem os mesmos cargos ou funções. O trabalho de valor igual será aquele em que

\footnotetext{
${ }^{18}$ Dos poucos contratos colectivos de trabalho referidos por Fátima Patriarca que, para além de não conter cláusulas restritivas, afirmava o princípio de 'a trabalho igual, salário igual', assinala-se o primeiro contrato dos lanifícios firmado em 1939 (Patriarca, 1990: 607).

19 Por exemplo, numa rede de hipermercados, na secção de peixaria, na qual em geral as empregadas são mulheres, não existe o posto de encarregado, mas na secção do talho, que em geral emprega sobretudo homens, já existe. Portanto, temos um mesmo posto, com as mesmas funções, mas como num caso em geral é uma mulher e no outro é um homem, a categoria é diferente e logicamente o salário também (comunicação pessoal de Ana Bela Dinis, da CGTP-IN, da equipa do Projecto NOW-Luna, já referido).
} 
as funções ou os cargos exercidos, embora de natureza diversa, são considerados equivalentes em resultado da aplicação de critérios objectivos de avaliação de funções (Decreto-Lei n. ${ }^{\circ} 426 / 88$, art. 3. ${ }^{\circ}$ ). O problema está, precisamente, em não existir em Portugal uma prática sistemática e difundida de recurso à avaliação de funções. A partir de 1987, com a adopção da norma europeia para a qualidade (especialmente a ISO 9002, direccionada para a garantia da qualidade na produção e instalações), estabeleceu-se a necessidade de generalizar pela primeira vez a análise de funções dos postos de trabalho, mas esta análise não tem sido conduzida com a preocupação de comparar salários entre categorias de trabalhadores. Tem sido utilizada apenas para fixar procedimentos de controlo da qualidade da produção e a sua difusão no sistema produtivo tem sido muito lenta.

Resta saber se a análise de funções, só por si, conduziria a uma mudança nos padrões de segregação e nos diferenciais de remuneração. Na verdade, o que muitos estudos mostraram é que mesmo quando se chega a uma reclassificação e se alteram as retribuições dos postos de trabalho ocupados por mulheres, estas revisões só têm sido aceites sob a condição de não subverterem a hierarquia existente entre trabalhadores (Doniol-Shaw e Lerolle, 1990: 6; Ferreira, 1998: 274). A alteração/erradicação da segregação deveria passar, no entanto, por reanalisar as funções da maior parte dos postos de trabalho, para que a sua retribuição fosse expurgada dos viés sexistas que marcaram a sua evolução passada. Há, porém, que, em primeiro lugar, definir novos critérios que permitam "medir" o desempenho em funções que envolvam a prestação de cuidados e de outros serviços, característicos da maior parte dos novos postos de trabalho ocupados por mulheres. Em segundo lugar, os sindicatos terão que se compenetrar da utilidade da avaliação de funções, algo que sempre recusaram no passado, em parte justificadamente, pois trata-se de um instrumento altamente manipulável.

\section{Os sindicatos e a igualdade entre mulheres e homens no trabalho e no emprego}

No estudo da OIT e da CISL, referido no início do texto (ILO, 1999), as 4 razões tidas como mais importantes, dentre as adiantadas pelos sindicatos no inquérito para a fraca mobilização sindical das mulheres trabalhadoras, foram as seguintes: a falta de sensibilização das mulheres faz com que não percebam em que é que os sindicatos as podem ajudar; a falta de coragem das mulheres para enfrentar as eventuais represálias das entidades patronais; a indisponibilidade das mulheres por causa das responsabilidades familiares por elas assumidas; e, em quarto lugar, o domínio da cultura masculina quer na organização quer nas actividades sindicais. Ao ler estas 
opiniões expressas pelos dirigentes sindicais quanto às razões que consideram mais importantes para a fraca participação das mulheres da vida sindical, não podemos deixar de pensar que eles revelam ainda uma fraca consciência dos efeitos das suas próprias práticas e das dos sindicatos em geral. Assim, as três razões tidas como mais importantes são claramente interpretadas como défices das mulheres (não percebem, têm medo, não têm tempo). Dois défices de atitude e o terceiro imputável a condições de vida. Só em quarto lugar surge uma referência a uma razão de ordem interna - a organização sindical e os seus modos de funcionamento não são acolhedores para as mulheres trabalhadoras. Há, pois, que assinalar que a actual intervenção sindical em prol de uma maior mobilização das mulheres passa pela transformação quer da cultura organizacional quer dos modos de funcionamento das estruturas sindicais.

É indubitável que o discurso actual das estruturas sindicais, ainda que muito tardiamente relativamente a outras instituições políticas, passou a incluir a promoção da igualdade de direitos no trabalho entre mulheres e homens. Assim o determinam as orientações internacionais de todas as instâncias que operam neste âmbito - desde a OIT à própria Confederação Europeia de Sindicatos - mas sobretudo assim o determinam as mudanças registadas a todos os níveis nas sociedades e nos mercados de trabalho. Já foi mencionada a crescente feminização do mercado de trabalho e dos próprios sindicatos, ao nível das bases, e há que acrescentar a intensificação da crítica feminista à cultura sexista e práticas sindicais segregadoras. Encarar as mulheres como reserva para o reforço das suas bases de apoio foi importante, como já foi apontado, assim como o é o facto de uma das principais reivindicações dos sindicatos na actualidade ser a redução do tempo de trabalho, como lógica de combate ao desemprego e de melhoria da qualidade de vida através de um maior equilíbrio entre o trabalho e as restantes esferas da vida familiar e pessoal. Temos, assim, assistido a um clamor de vozes que reclama a aproximação do movimento sindical a outros movimentos sociais, nomeadamente os movimentos das mulheres (Gorz, 1999: 54; Cohen e Rai, 2000: 7). ${ }^{20}$

${ }^{20}$ Em Outubro de 2000, a grande manifestação que teve lugar em Lisboa, integrada na Marcha Mundial das Mulheres, uma iniciativa realizada em muitos países e coordenada a partir de uma ONG do Quebeque, foi a primeira grande mobilização pública das organizações sindicais, pelo menos eu tendo a vê-la assim, com as lutas das mulheres, em Portugal. Não resistiram, porém, à tentação da hegemonização e o resultado foi tudo menos positivo. Para que a aproximação referida ocorra é necessário que o movimento sindical se consciencialize que, apesar de melhor organizado do que os outros, ele é um entre outros e as lutas que mobilizam os restantes são tão legítimas como a sua própria. 
O impacte destas transformações na orientação da acção sindical tem sido, no entanto, muito lento. Segundo o estudo recente promovido pela Confederação Europeia de Sindicatos (CES), são ainda muito poucos os sindicatos que consagraram nos seus estatutos o princípio da igualdade entre os sexos, mesmo na sua versão mais restritiva de igualdade de oportunidades, e menos ainda aqueles que têm programas de acção ou políticas específicas orientadas para a aplicação deste princípio. A própria CES só em 1995 formulou o seu primeiro plano global para a igualdade. No que se lhe seguiu 4 anos depois, os objectivos ainda são algo limitados e especialmente vagos: 1 . assegurar uma representação paritária entre mulheres e homens nos orgãos de direcção das estruturas sindicais e nas equipas de negociação colectiva; 2 . incorporar a problemática da igualdade entre mulheres e homens em todas as facetas da vida sindical; 3 . alcançar a igualdade de remuneração entre mulheres e homens. Em termos concretos, a CES tem promovido o levantamento de informação com o objectivo de conhecer melhor o problema e tem organizado algumas conferências em torno das desigualdades entre os sexos no que diz respeito quer à vida laboral, quer à vida sindical. Para além destas iniciativas, a CES tem-se limitado a algum trabalho de lobbying junto da Comissão Europeia e Parlamento Europeu.

Entende-se o fraco alcance destas iniciativas se tivermos em conta que, já desde a década de 1970, algumas estruturas sindicais deram início a campanhas para a igualdade de mulheres e homens. Por exemplo, a Confederação Internacional dos Sindicatos Livres (a já referida CISL) lançou em 1978 a campanha Igualdade para as Mulheres nos Sindicatos: Um Programa de Acção para a Integração das Mulheres nas Organizações Sindicais e a Confederação dos Sindicatos Ingleses (TUC) adoptou em 1979 a Carta para a Igualdade das Mulheres nos Sindicatos (Lawrence, 1994: 31). As políticas internas das estruturas sindicais mostraram ser muito limitadas. Muitas das Comissões de Mulheres surgidas na década de 1980 sobreviveram mal, sem orçamentos próprios e acantonadas nos "assuntos de mulheres" em comissões específicas, não forçosamente por sua culpa como é evidente. ${ }^{21}$ No decurso do tempo, a perpetuação das situações discriminatórias tornou claro que os "assuntos de mulheres" deveriam passar a constituir matéria de negociação colectiva, mas para serem eficazes neste campo as equipas negociadoras deveriam passar a integrar mais mulheres e para isso era necessário que estas não fossem apenas sindicalizadas mas se tornassem sindicalistas, pois a experiência mostra que são as comissões em que existe

\footnotetext{
${ }^{21} \mathrm{Na}$ CGTP-IN, por exemplo, a Comissão Nacional de Mulheres, que existe há cerca de 20 anos, não possui um estatuto de órgão, é uma comissão específica sem orçamento próprio. Para os jovens e os reformados, no entanto, já existem órgãos e orçamentos próprios.
} 
uma forte presença das mulheres que dão prioridade às questões da igualdade no trabalho e no emprego (Donaghy, 1995: 191). Daí todo o conjunto de medidas advogado pelas políticas igualitárias no sentido de se alterarem as regras de funcionamento, alterando as horas de reunião e/ou proporcionando serviços de acolhimento de crianças, por exemplo, e de preparar mulheres para a actividade sindical, proporcionando-lhes acções de formação e reservando para elas alguns lugares nos orgãos dirigentes sindicais. Pouco a pouco, a fraca presença das mulheres nas estruturas sindicais deixa de ser vista apenas como um défice democrático e um indicador de crise de representação. A necessidade de reforçar essa presença adquiriu, entretanto o estatuto de condição indispensável à maior eficácia na negociação colectiva, tendo em vista o interesse de ambos os sexos.

Este é o passo que mais resistências suscita. Vem a propósito relembrar aqui declarações de algumas das mais destacadas sindicalistas portuguesas a um semanário (Expresso, 1 de Maio de 1998). Manuela Teixeira, dirigente da UGT, relata a resistência que enfrentou há 20 anos quando começou a sobressair como dirigente sindical. Para além de referir que "a Federação Nacional dos Sindicatos de Educação (FNE) esteve mais de um ano sem secretário-geral devido ao facto de os sindicatos dirigidos por homens terem dificuldade em aceitar uma liderança feminina”, a sindicalista conta ter ouvido nessa altura da boca de um colega seu que a razão pela qual o seu sindicato havia rompido um determinado processo negocial se devia ao facto de que "não estava a aguentar ter uma mulher a coordenar uma equipa negociadora”. Se há 20 anos era assim, agora, verifica-se que "a maior parte das pessoas não gosta de ver mulheres em cargos de direcção ... e se tivessem um homem disponível quando há dois anos insistiram comigo para eu avançar nem me teriam ido buscar", como constatava a então Presidente do Sindicato dos Jornalistas, Diana Andringa (ibid.).

É neste contexto que se chega ao século XXI com uma persistente fraca representação das mulheres nas estruturas sindicais. No citado estudo da CES (1999), das 42 confederações, apenas uma é presidida por uma mulher (a SACO da Suécia) ${ }^{22}$ e apenas 4 têm mulheres na posição de secretárias-gerais (a FGTB da Bélgica, a CFDT da França, a MHP da Holanda e a TCO da Suécia). ${ }^{23}$

\footnotetext{
${ }^{22}$ SACO é a sigla para Sveriges Akademikers Centralorganisation, que podemos traduzir por Organização Central das Associações de Profissionais.

${ }_{23}$ Tradução aproximada de siglas: FGTB corresponde a Federação Geral de Trabalhadores da Bélgica, CFDT é a Confederação Francesa do Trabalho, MHP é a Confederação dos Sindicatos de Quadros e Gestores da Holanda e a TCO é a sigla da Organização Central de Trabalhadores da Função Pública e de Escritórios.
} 
A mudança "natural" tem provado ser de difícil concretização, uma vez que o aumento da sindicalização das mulheres não se tem traduzido no correspondente acréscimo da influência feminina nos postos de decisão e de liderança das organizações sindicais. Além de que há que atentar nas transformações que o próprio emprego feminino tem sofrido. Apesar dos níveis de segregação sexual que persistem, hoje deixa de ter sentido guardar a imagem da mulher trabalhadora como uma jovem desqualificada em empregos de alta rotação (como faz por exemplo Rosa: 1998). A vida activa das mulheres é cada vez mais longa e as suas carreiras não se incluem todas no segmento secundário do emprego. Constata-se, pois, um progressivo reconhecimento de que, neste quadro de mudanças, a situação actualmente vivida nas organizações sindicais tem que ser transformada com base em medidas voluntaristas.

Daí justificarem-se os planos de acção para mudar as próprias estruturas sindicais, para que assim possam também mudar as realidades laborais, pois a história do movimento sindical mostra que as estruturas sindicais podem muito facilmente reproduzir as desigualdades que informam as organizações que tentam reformar (Donaghy, 1995: 191). A intervenção tem que ser feita a todos os níveis e em simultâneo, pois todas os vectores das desigualdade entre os sexos estão interligados.

\section{As políticas sindicais de dessegregação do mercado de trabalho em Portugal}

Um dos aspectos centrais na acção sindical de combate às desigualdades entre homens e mulheres passa pela imposição/negociação de práticas dessegregadoras do mercado de trabalho, especialmente no que respeita ao acesso ao emprego e à formação e à progressão na carreira. Relativamente a cada um destes aspectos, existe uma panóplia de iniciativas passíveis de serem negociadas que vão desde a regulamentação dos procedimentos a adoptar nas várias fases do recrutamento e da promoção ao estabelecimento de critérios que promovam o acesso das mulheres a áreas e cargos em que estejam sub-representadas. ${ }^{24}$ Há que assinalar nesta matéria a extraordinária

\footnotetext{
${ }^{24}$ Alguns organismos internacionais, sindicais e não sindicais (por exemplo a CISL e a OIT), têm vindo a recomendar a adopção de medidas específicas tendo em vista o aumento da participação das mulheres nas estruturas sindicais, que vão desde as revisões estatutárias (criar lugares reservados, definir que a presidente da Comissão de Mulheres deve ter assento automático no órgão executivo máximo, etc.), à adopção de planos de acção específicos, às medidas de divulgação $e$ publicidade, à formação de quadros e à adaptação dos modos de funcionamento (ILO, 1999). Entre as estratégias mais comuns adoptadas, encontramos: declaração política de adesão ao princípio da igualdade de oportunidades; auto-avaliação das estruturas sindicais para identificar os factores que influenciam a participação das mulheres nos diferentes níveis organizacionais; formação sindi-
} 
importância de que se revestiu o estudo sobre Igualdade de Oportunidades e Negociação Colectiva na Europa da iniciativa da Fundação Europeia para a Melhoria das Condições de Vida e do Trabalho. ${ }^{25}$

Em Portugal, podemos ter uma ideia da intervenção sindical inovadora neste domínio através de dois textos de fontes sindicais incluídos no número 6 da revista Sociedade e Trabalho, publicado em finais de 1999, dedicado à Igualdade de Oportunidades. Um deles é relativo à acção da UGT (Comissão de Mulheres da UGT, 1999) e o outro à da CGTP-IN (CGTP-IN, 1999). A acção da UGT nesta matéria enquadra-se perfeitamente no perfil de iniciativas relatadas para a Confederação Europeia de Sindicatos: inscrição da equidade entre os sexos nos estatutos, recomendações aos sindicatos sobre a composição sexual mais equilibrada dos respectivos orgãos sociais e equipas negociadoras e organização de encontros, colóquios e conferências para actividades de difusão destes objectivos. Se analisarmos o texto de divulgação já referido, vemos que ele não contém mais do que uma declaração de boas intenções, isto é, de uma enunciação normativa daquilo que deveria ser feito. O seu Plano de Acção para a Igualdade, anunciado no Congresso de 2000, e disponível na sua página na internet (http://www.ugt.pt/plano.htm), procura no essencial corresponder às orientações emanadas do Plano para a Igualdade da CES, fixando prioridades, metas e prazos. Os 4 objectivos propostos são: o aumento da participação das mulheres nos órgãos de tomada de decisão e nas equipas de negociação; a integração das questões das relações sociais de sexo em todas as práticas sindicais (mainstreaming); o estabelecimento da igualdade salarial; e o equilíbrio entre a vida profissional e a vida familiar. Determina-se ainda que tanto a UGT como os sindicatos seus filiados deverão submeter ao Secretariado Nacional um relatório de avaliação em 2002, a meio do mandato, para que sejam analisadas as iniciativas tomadas. A única meta claramente definida neste plano diz respeito ao primeiro objectivo identificado e estabelece que o limiar de representação para que se aponta deve "ser proporcional à percentagem de mulheres

cal específica para mulheres; formação em igualdade de oportunidades para sindicalistas, dirigentes e não-dirigentes; inclusão de questões relacionadas com as diferenças salariais, a segregação do emprego, o assédio sexual e as licenças especiais relacionadas com a maternidade, paternidade e assistência à família na negociação colectiva; criação de órgãos específicos ou estruturas de igualdade (comissões, departamentos, conferências e congressos); reserva de lugares e/ou quotas nos órgãos de tomada de decisão e nas equipas de negociação, destinados ao sexo menos representado (por exemplo, Date-Bah, 1997: 210).

${ }_{25}$ Os resultados deste estudo foram divulgados numa excelente síntese de L. Dickens, que podemos considerar um autêntico livro de texto sobre as articulações entre a igualdade de oportunidades e a negociação colectiva (Dickens, 1999). 
inscritas em cada sindicato". O grau de efectivação deste plano não será eventualmente muito expressivo, mas a sua existência é já em si um sinal positivo, ao fornecer às e aos sindicalistas sinais claros da necessidade de mudar uma realidade ainda altamente penalizadora para as mulheres.

A CGTP-IN, por seu turno, dá conta de um projecto NOW-LUNA (1996-2000), no âmbito do qual foram desenvolvidas actividades de uma natureza mais sistemática e continuada de intervenção na realidade das situações de trabalho. O projecto abrangeu uma diversidade de iniciativas que vão desde a monitorização dos acordos de contratação colectiva para os sectores abrangidos com o objectivo de avaliar o seu impacte em ambos os sexos, à elaboração de estudos de diagnóstico de recursos humanos, com especial atenção à situação de discriminação das mulheres em 16 empresas e 4 organismos públicos que aderiram ao projecto, até à formação em questões de igualdade entre os sexos de dirigentes, delegados e delegadas sindicais. Nas empresas que aderiram ao projecto foram acordados protocolos com acções positivas para a igualdade, tendo sido abrangidos um total de 33.124 trabalhadores dos quais 17.519 são mulheres (CGTP-IN, 1999: 109). Para cada empresa foi acordado um conjunto de acções positivas adaptado às situações concretas de desigualdade detectadas em cada uma. Grosso modo, no entanto, as áreas de intervenção foram desde o acesso aos postos de trabalho, formação profissional, efectividade dos direitos de maternidade e paternidade, higiene e segurança no trabalho, progressão nas carreiras profissionais, salários e condições de remuneração, vínculo contratual, apoios sociais, horários de trabalho e formas de organização. Algumas das medidas referidas em cada uma destas áreas não vão além do compromisso de cumprir a lei. É o que acontece quando uma empresa se propõe estabelecer o horário de 40 horas semanais e 8 horas diárias, ou quando outra se propõe distribuir máscaras ou fazer exaustão de cheiros, por exemplo. Outras, porém, são verdadeiramente inovadoras e lançam sementes para a transformação das relações sociais entre os sexos no trabalho. É o caso da criação de comissões para a igualdade de oportunidades e tratamento no trabalho e no emprego, ou o recrutamento privilegiado de mulheres, quando em igualdade de conhecimentos e aptidões, para funções de níveis superiores, categorias mais qualificadas e profissões tradicionalmente masculinas (CGTP-IN, 2000: 33-38). Foi no âmbito deste projecto que o Casino do Estoril começou a contratar mulheres para a função de croupier e estendeu o prémio de domínio de línguas estrangeiras às barmaids do casino, que a OPEL começou também a contratar mulheres para a sua secção de pintura-auto e projectou contratar algumas para a sua linha de montagem e que a 
Câmara de Lisboa contratou as primeiras jardineiras e cantoneiras de limpeza. As acções de formação em igualdade constituíram também uma dimensão importante da intervenção no âmbito deste projecto, tendo abrangido 228 trabalhadoras e 38 trabalhadores. A formação inicial para a gestão sindical também foi incluída, tendo nela participado 33 mulheres que assim ficaram certamente mais preparadas para participarem na vida sindical.

Estas são intervenções com um potencial transformador que ultrapassa o impacte previsível nos sujeitos directamente envolvidos, contribuindo para uma mudança cultural nas relações laborais tanto entre trabalhadores/as como entre estes/as e as entidades empregadoras. É este necessariamente o caminho a prosseguir.

Podemos visualizar os obstáculos que um empreendimento destes suscita, quando lemos o trabalho de Elísio Estanque no sector do calçado (2000). As discriminações que as mulheres sofrem na fábrica estudada nunca são mencionadas pelo autor como sendo objecto do discurso das pessoas com que ele contactou no seu trabalho de terreno, nem esta discriminação é integrada na sua análise da fraca mobilização sindical. Não existindo uma pressão das mulheres no sentido de uma maior equidade no trabalho e no emprego, as medidas voluntaristas resultarão sempre numa estratégia, mais ou menos estéril, de imposição de cima para baixo de normas e valores.

\section{Comentário final}

A acção segregadora, e até mesmo excludente, dos sindicatos relativamente às mulheres trabalhadoras é bem ilustrativa da importância do papel que as relações na produção, no sentido que lhes confere Burawoy, têm na configuração das situações concretas de divisão sexual do trabalho. Estas relações estão imbuídas da cultura sexista que domina as nossas sociedades e, portanto, têm ajudado a construir lugares de trabalho "hostis" para as mulheres trabalhadoras. No passado, a acção sindical foi marcada pela ideologia do homem "provedor" e da mulher "cuidadora", o que foi determinante na aceitação de salários inferiores para as mulheres e na integração diferenciadora nos locais de trabalho, numa estratégia segregadora a que Judith Lorber, ao analisar as dificuldades de inserção das mulheres na profissão médica, se referiu como o "fenómeno Salieri". A sua fonte de inspiração é a peça Amadeus de Peter Shaffer, na qual Salieri, o compositor oficial da côrte, recomenda ao imperador que conceda um lugar a Mozart ao mesmo tempo que sugere que este seja de baixo nível e parco salário (apud Epstein, 1988: 156). 
Apenas num segundo momento, o movimento sindical assumiu que a defesa do emprego feminino em igualdade de remuneração era a estratégia desejável à preservação dos interesses dos seus sindicalizados (homens). Apesar dos sinais de inversão de política apresentados na última secção deste estudo, vai ser certamente difícil aprofundar a luta pela igualdade, dado o conjunto de mudanças em curso nas relações laborais, as resistências das entidades empregadoras e o "apego cultural" à discriminação tanto das mulheres como dos homens. O crescente individualismo apontado por todos os analistas das relações de trabalho é um obstáculo ponderoso, não apenas pelo que ele significa de falta de identificação com interesses colectivos, até porque os indivíduos podem sindicalizar-se numa atitude perfeitamente individualista e instrumental de defesa dos seus interesses pessoais, mas pelo facto de ele decorrer de situações laborais únicas, dificilmente padronizáveis e negociáveis colectivamente.

A emergência do paradigma da "gestão dos recursos humanos" nas organizações de trabalho veio legitimar cada vez mais a recusa à intromissão dos sindicatos e dos seus representantes nas relações de trabalho, acentuando as tendências individualistas (Rosa, 1998: 136). Os novos estilos de gestão dificultam a apreensão das reais condições contratuais de cada indivíduo, tornando a construção colectiva de interesses mais difícil. Apesar da necessidade de contar com a mão-de-obra feminina para alargar a sua base social, é notório que as organizações sindicais conhecem muito pouco sobre as modalidades e a prevalência da participação sindical das mulheres e até sobre as suas condições de trabalho e de vida e por isso têm ainda mais dificuldades em as mobilizar para a intervenção sindical. Podemos avaliar o quanto há ainda por fazer quando uma das medidas mais citadas pelas organizações sindicais na sua estratégia de mainstreaming é a desagregação da informação segundo os sexos nos levantamentos das situações a realizar futuramente.

Se temos, por um lado, o individualismo e a gestão dos recursos humanos, por outro lado, temos as relações de emprego e o correspondente colectivismo. Entre a atitude instrumental perante o trabalho e a gratidão por conservar o emprego, aos sindicatos exige-se que assumam um papel cada vez mais interveniente na promoção da igualdade entre mulheres e homens tanto no acesso e na estruturação das carreiras profissionais, como na redução e flexibilização do tempo de trabalho, ou ainda na criação de estruturas de apoio à vida pessoal e familiar. As condições são adversas, mas, pelo que pudemos ver ao longo deste ensaio, as organizações sindicais, enquanto elos de um dos mais bem organizados movimentos sociais e enquanto elementos fundamentais das sociedades actuais, não podem escapar-se aos efeitos das mudanças verificadas na situação das mulheres e 
parecem estar agora a ensaiar os primeiros passos no sentido de reexaminarem as suas atitudes e comportamentos relativamente às mulheres quer no local de trabalho, quer nas próprias estruturas sindicais, abandonando de vez o seu papel de Salieri.

\section{Referências Bibliográficas}

André, Maria Helena (1999), "A igualdade de oportunidades: Um desafio para o século XXI - Perspectiva da Confederação Europeia de Sindicatos”, Sociedade e Trabalho, 6,57-66.

André, Isabel Margarida (1995), "Les syndicats et les femmes au Portugal après le 25 d'avril", in EPHESIA (org.), La place des femmes - Les enjeux de l'identité et de l'égalité au regard des sciences sociales. Paris: Éditions la Découverte, 486-489.

CES (1999), “The 'Second Sex' of European Trade Unionism”, estudo coordenado por Ada Garcia da Univ. Cat. de Louvaina. Consultado em Janeiro de 2002 e disponível $\mathrm{em}:<\mathrm{http}$ //www.etuc.org/EN/DOSSIERS/EQUALITY/women_in_trade_unions/ The Second Sex_Study.cfm>.

CGTP-IN (1999), "Actividades CGTP na área da igualdade de oportunidades - Projecto NOW-LUNA”, Sociedade e Trabalho, 6, 109-112.

CGTP-IN (2000), Derrubar barreiras, construir igualdade - Caminhar, resistir, convencer. Lisboa: CGTP-IN, Relatório Projecto NOW-LUNA 1996-2000.

Cohen, Robin; Rai, Shirin M. (orgs.) (2000), "Global Social Movements - Towards a Cosmopolitan Politics”, in Robin Cohen; Shirin M. Rai (orgs.), Global Social Movements. New Brunswick, N.J.: The Athlone Press, 1-17.

Cohn, Samuel (1985), The Process of Occupational Sex-typing - The Feminization of Clerical Labor in Great Britain. Philadelphia: Temple University Press.

Comissão de Mulheres da UGT (1999), "Actividade UGT na área da igualdade de oportunidades - Apostar na diferença, escolher a qualidade”, Sociedade e Trabalho, 6, 104-107.

Cristovam, Maria Luisa (1998), "Equal Opportunities Dominate Bargaining in Footwear Industry", EIRO, Janeiro, European Foundation for the Improvement of Living and Working Conditions.

Crompton, Rosemary; Sanderson, Kay (1990), Gendered Jobs and Social Change. London: Unwin Hyman.

Date-Bah, Eugenia (1997), "The Trade Unions and Women Workers: Current Trends", in Eugenia Date-Bah (org.), Promoting Gender Equality at Work - Turning Vision into Reality. London: Zed Books, 209-224.

Dickens, Linda (1999), Igualdade de Oportunidades e Negociação Colectiva na EuropaAnálise do Processo de Negociação. Lisboa: Ministério do Trabalho e da Solidariedade, Estudos - Série C - Trabalho, 14, traduzido para a CITE. 
Donaghy, Rita (1995), “Trade Unions and Equal Opportunities”, in Jenny Shaw; Diane Perrons (orgs.), Making Gender Work - Managing Equal Opportunities. Buckingham, Philadelphia: Open University Press, 178-192.

Doniol-Shaw, Ghislaine; Lerolle, Anne (1990), "L'évolution du rapport genre-qualification: questions d'identité et de pouvoir”, comunicação apresentada em 12th International Conference of Sociology, Madrid.

Epstein, Cynthia Fuchs (1988), Deceptive Distinctions - Sex, Gender, and the Social Order. New Haven, London, New York: Yale University Press \& Russell Sage Foundation.

Estanque, Elísio (2000), Entre a Fábrica e a Comunidade: Subjectividades e Práticas de Classe no Operariado do Calçado. Porto: Afrontamento.

Ferreira, António Casimiro; Costa, Hermes Augusto (1998/99), "Para uma sociologia das relações laborais em Portugal”, Revista Crítica de Ciências Sociais, 52/53, 141-171.

Ferreira, Virgínia (1993), "Padrões de Segregação das Mulheres no Emprego - Uma Análise do caso Português no Quadro Europeu”, in Boaventura de Sousa Santos (org.), Portugal: Um retrato singular. Porto: Afrontamento, 233-260.

Ferreira, Virgínia (1998), "Positive Action and Employment Segregation”, in Virgínia Ferreira; Teresa Tavares; Sílvia Portugal (orgs.), Shifting Bonds, Shifting Bounds Women, Mobility and Citizenship in Europe. Oeiras: Celta, 271-280.

Gorz, André (1999), “A New Task for the Unions: The Liberation of Time from Work”, in Ronaldo Munck; Peter Waterman (orgs.), Labour Worldwide in the Era of Globalisation - Alternative Union Models in the New World Order. Hampshire: Macmillan Press, 41-63.

Hartmann, Heidi (1976), "Capitalism, Patriarchy and Job Segregation by Sex", in Martha Blaxall; Barbara Reagen (orgs.), Women and the Workplace: The Implications of Occupational Segregation. Chicago: University of Chicago Press, 137-169.

Hyman, Richard (1994), "Trade Unions and the Disagregation of the Working Class", in Marino Regini (org.), The Future Labour Movements. Thousand Oaks: Sage, 150-168.

ILO (1999), "The Role of Trade Unions in Promoting Gender Equality and Protecting Vulnerable Women Workers - First report of the ILO-ICFTU”. Survey, Geneva: International Labour Organisation. Consultado em 1999 e disponível em: <http:// www.ilo.org>.

Larangeira, Sônia; Ferreira, Virgínia (2000), “Excluídos e beneficiários dos processos de reestruturação: estudo comparativo da regulação do emprego no sector bancário em Portugal e no Brasil”, Revista Crítica de Ciências Sociais, 57/58, 53-85.

Lawrence, Elizabeth (1994), Gender and Trade Unions. London: Taylor \& Francis.

Lima, Marinús Pires de (1991), "Relações de trabalho, estratégias sindicais e emprego", Análise Social, XXIV(5. $)$, 114, 905-943. 
Milkman, Ruth (1987), Gender at Work: The Dynamics of Job Segregation by Sex during World War II. Champaign: University of Illinois Press

Murgatroyd, Linda et al. (orgs.) (1984), Localities, Class and Gender. London: Pion.

Parkin, Frank (1974), "Strategies of Social Closure in Class Formation", in Frank Parkin (org.), The Social Analysis of Class Structure. London: Tavistock.

Patriarca, Fátima (1990), Processo de implantação, lógica e dinâmica de funcionamento do corporativismo em Portugal. Lisboa: Instituto de Ciências Sociais, Tese de Doutoramento (mimeografado).

Patriarca, Fátima (1994), "A regulamentação de trabalho nos primeiros anos do Regime Corporativo”, Análise Social, XXIX(4. $\left.{ }^{\circ}\right), 128,801$ - 839.

Pimentel, Irene Flunser (2000), História das organizações femininas no Estado Novo. Mem Martins: Círculo de Leitores.

Rosa, Maria Teresa Serôdio (1991), "As mulheres e o sindicalismo”, Organizações e Trabalbo, 5/6, 89-112.

Rosa, Maria Teresa Serôdio (1998), Relações sociais de trabalho e sindicalismo operário em Setúbal. Porto: Afrontamento.

Santos, Boaventura de Sousa (1989), O Estado e a sociedade em Portugal (1974-1988). Porto: Afrontamento.

Scott, Gillian (1998), Feminism and the Politics of Working Women - The Women's Co-operative Guild, 1880s to the Second World War. London: University College London Press.

Walby, Sylvia (1990), Theorizing Patriarchy. Oxford: Basil Blackwell.

Watson, Tony J. (1987), Sociology, Work E Industry. London: Routledge [1980].

Zylberberg-Hocquard, Marie Hélène (1978), Féminisme et syndicalisme en France. Paris: Anthropos. 